\title{
Designing Class Participation Experiences for the Introverted Student
}

By: Jeanne Merkle Sorrell, DAEd Hazel N. Brown, EdD

Sorrell, J. M., \& Brown, H. N. (1995). Designing class participation experiences for the introverted student. Nurse Educator, 20(4),30-34.

Made available courtesy of Lippincott, Williams \& Wilkins:

http://www.nurseeducatoronline.com/pt/re/nurseeducator/home.htm;jsessionid=J2gJX1nmmJpb9

grGJLnQnlCpsl2CLNPLqS81QnMyyctTQ1WWHGnM!-1690570675!181195629!8091!-1

This format of the article is not the final published version.

***Note: Figures may be missing from this format of the document

\begin{abstract}
:
Class participation for students is such a common expectation of nurse educators that it is easy to overlook the need to tailor class participation activities to individual student needs. An understanding of the various temperaments of individuals, especially preferences related to extroversion and introversion, can help nurse educators to plan class participation experiences that foster skills in critical thinking and enhance personal growth.
\end{abstract}

Article:

Class Participation: 25\% of course grade. Any student who has difficulty participating in class discussions, please see faculty for guidance.

Probably no nurse educator has written a statement such as the aforementioned one.

Traditionally, we use class participation as an important criterion for overall student performance in a course, but may not consciously think through our own beliefs about the value of class participation, how to tailor class participation activities to individual students' needs, or how to assess this part of student performance for different types of students.

As nurse educators and authors discussing this problem, we realized that we are opposite temperament types, and that we tend to plan class participation activities for our students according to guidelines that are comfortable for our own individual temperaments. This realization reflects the purpose of this article, which is to present strategies for nurse educators to use in designing class participation activities that benefit students of the introverted temperament type described by Jung. ${ }^{1}$ Because introverted temperament types constitute only approximately $25 \%$ of the population, ${ }^{2}$ these students often are required to fit themselves into classroom activities designed for the extroverted student.

One nurse educator describes her memories of "class participation" requirements as a nursing student:

I remember how I would scan the nursing course syllabus at the beginning of each semester to see what I would need to do in order to get an "A" in the course. When I would see "class participation" listed as a percentage of the 
course grade, I knew I was in trouble. Realizing that I would never get above a "B" in that category (I thought I deserved that much for showing up in class), I would work out strategies to excel on papers and tests for the course.

For years, in elementary and high school, I had earned high grades in spite of my quiet and painfully shy temperament that kept me from speaking in class; I even graduated as class valedictorian. In nursing school, however, I was suddenly faced with the realization that I was very inadequate in one area: oral class discussions. I knew I needed to talk in my nursing classes, so I prepared. I poured over preclass readings, preparing appropriate comments to make in class. I prepared questions to ask the instructor during class, and tried to prepare answers for questions I thought she might ask. All of this made me very knowledgeable about the readings, but it did not help me speak in class. I sat in class, trying to mobilize my courage to jump into the lively discussion, but there always seemed to be a classmate who would answer a question or make a comment just as I was ready. I became so anxious during class that I was unable to follow the flow of the discussion, and the more anxious I became, the harder it was to speak. After class, I would drive home exhausted and depressed that I could be such a failure at something I wanted so much to do.

This example illustrates the need for nurse educators to consider students' (and their own) basic temperament types in designing class participation experiences. This nurse educator's basic temperament hindered her from demonstrating her academic potential in a common academic arena-class participation. She was a lone introvert trying to stay afloat in a sea of extroverts, and her "intuitive" and "feeling" nature accentuated the poignancy and disappointment of her failure at something that seemed so easy for her peers.

\section{Temperament Types}

Keirsey and Bates, in their book, Please Understand $M e,{ }^{2}$ state that individuals have basic temperament types by which they interact with their world, and that these basic "ways of being" are not likely to change, even though we might like someone to be more like us. In fact, there is no reason for us to try to change those people of other temperaments because the differences often can serve to our benefit. Individuals with different temperaments interact with and relate to the world differently, and access and use information differently. Individuals of each temperament need to be understood.

Keirsey and Bates, ${ }^{2}$ adapting the work of Myers and Briggs, ${ }^{3}$ and integrating theories of Jung related to basic temperaments 1 present an 'overview of basic temperament types. They state that each individual's temperament can be described through the following four pairs of preferences:

\section{Extroversion/introversion; \\ Intuition/sensing; Thinking/feeling; Judging/perceiving.}

The research teams of both Myers and Briggs and Keirsey and Bates have designed tests that can be given to students to determine their specific temperament type, but this may not be practical for nurse educators in the classroom. A general understanding of the basic characteristics of these four pairs of preferences, however, can enhance faculty sensitivity to the potential presence in their classroom of students with various temperaments.

\section{Extroversion/Introversion}


Jung believed that the extroversion/introversion preference was the most important of the four preference pairs ${ }^{2}$ because it indicates our preferences in how we interact with the outside world. It is important to recognize that neither extroversion nor introversion has a negative connotation; they simply are objective terms for describing different temperaments.

Extroverts, who comprise approximately $75 \%$ of the population, prefer to direct their energies to things and people outside themselves. Extroverts tend to be seen as sociable because they are energized by other people; talking, playing, and working with people "charges their battery." These individuals enjoy the excitement of classroom discussions because they exchange ideas with peers and gain renewed energy.

Introverts, on the other hand, obtain their energy from within themselves, not from others, so they need privacy and solitude to regain energies drained from active contact with others. They are likely to enjoy the solitary time dedicated to pre- class preparation, but may be exhausted by the pressure of trying to interact with peers in the classroom. Because introverts are found in only approximately $25 \%$ of the population (and possibly less in nursing classrooms), they may feel alone and inferior as they try to swim against the tide to be more like their peers.

\section{Intuition/Sensing}

The intuition/sensing pair of preferences is responsible for how individuals receive, or take in, information, and is responsible for more miscommunication, misunderstanding, and denigration than any of the other three types. ${ }^{2}$ This preference often places a wide gulf between some people, who may find it difficult to understand why persons of an opposite preference act as they do.

The person with a preference for sensing often has a practical, no-nonsense approach to learning. These individuals, making up approximately $75 \%$ of the population, are interested in facts, experience, and reality. They use all their five senses to take in information and demonstrate good observation skills. They reach conclusions systematically, content to use standard ways of solving problems. One study found that approximately $70 \%$ of nurses prefer sensing. ${ }^{4}$ Students with a sensing preference enjoy the opportunity to learn facts that have practical relevance to their lives, and may be impatient with approaches that seem too abstract and remote.

The individual with an intuitive preference, found in approximately $25 \%$ of the population, often is bored with standard ways of solving problems, preferring to use intuitive skills to explore new imagined possibilities. The intuitive person enjoys vivid imagery and figurative language found in poetry, fantasy, and fiction, and dislikes repetition and routine. Intuitive people sometimes find ideas coming to them as a complete whole, although they are unable to explain how they "knew." Because of their reliance on this highly developed "sixth sense," they may fail to observe aspects of their environment that seem obvious to others. Students in the classroom with an intuitive preference can help peers see new approaches and opportunities in long-accepted assumptions. They enjoy opportunities to integrate creative reading and writing into their class work and to participate in creative problem-solving activities.

\section{Thinking/Feeling}

This set of preferences affects how individuals use information. The thinking type prefers an impersonal, objective basis for decision making, whereas the feeling type is more comfortable 
with judgments that reflect a personal basis.' A thinking type may be seen by a feeling type as impersonal, remote, and cold; a feeling type may be seen by a thinking type as too emotional, illogical, and unable to take a firm stand on an issue. Both temperament types are capable of making either thinking or feeling judgments, but the specific type reflects their usual preference in decision making. Most women exhibit the feeling temperament; thus, nurse educators need to be aware of the potential of the lone thinking type in their classroom.

\section{Judging/Perceiving}

The judging/perceiving preference accounts for how we relate to the outer world. These two preferences appear to be equally distributed in the population. ${ }^{2}$ Judging types prefer closure in their lives; they establish deadlines, take them seriously, and expect others to take them seriously. They have a strong work ethic, enjoy planning ahead to meet commitments, and feel a sense of urgency and comfort in making decisions. In

Table 1. Possible Temperament Types and Approximate Percentage of Representation in Population

\begin{tabular}{llll}
\hline INFP-1 $\%$ & ISFP-5 $\%$ & INTP-1\% & ISTP-5\% \\
ENFP-5 $\%$ & ESFP-13\% & ENTP-5\% & ESTP-13\% \\
INFJ-1\% & ISFJ-6\% & INTJ-1\% & ISTJ-6\% \\
ENFJ-5\% & ESFJ-13\% & ENTJ-5\% & ESTJ-13\% \\
\hline
\end{tabular}

$\mathrm{E}=$ extroversion $\mathrm{S}=$ sensing; $\mathrm{T}=$ thinking; $\mathrm{P}=$ perceiving; $\mathrm{I}=$ introversion; $\mathrm{N}=$ intuition; $\mathrm{F}$ $=$ feeling; $\mathrm{J}=$ judging.

Adapted from Keirsey and Bates (1978). ${ }^{2}$

other words, they often are an instructor's dream. They are well organized and need little reminding to complete assignments on time.

The person with the perceiving temperament, on the other hand, likes to keep possibilities open when asked to make a decision, wanting more data. When forced to make a decision, they may feel somewhat restless and uneasy. Perceiving types may be seen by judging types as indecisive, purposeless, and procrastinating, but their basic temperament leads them to resist deadlines because they enjoy the opportunity to gather more data and the rush of excitement that comes from last-minute action.

Their preparation for class participation may not be immediately evident to faculty members because they avoid the quick and obvious response to a question and may be still pondering the question when the rest of the class has moved on to the next point. Perceiving types have a "play ethic" that is important to them, and they believe that a work process, such as classroom activities, should be enjoyable. Whereas judgment types are outcome oriented, perceiving types are process oriented. If allowed the freedom to relate in class according to their preference, perceiving types can make important contributions to class members' enjoyment of the process of attaining desired class outcomes.

Jung's theories state that each individual's temperament is comprised of four preferences drawn from the aforementioned pairs, with 16 possible combinations. For convenience of discussion, each temperament can be categorized by four letters (Table 1). Nurse educators must recognize 
that some temperament types make up the majority of the students in their classes, whereas someone with a rare temperament type may be alone in the class. The nurse educator who described her student experiences at the beginning of this article has an introverted/intuitive/feeling/perceiving temperament that is found in only $1 \%$ of the population. Knowing this, it is easy to understand her frustration at being so different from her peers, a difference she (and her instructors) interpreted as inferior. Table 1 indicates other rare temperament types found in the general population.

\section{Designing Class Participation Experiences for the Introverted Student}

It is important to recognize that temperament types developed from Jung's work are only one approach for coming to understand students' individual orientations to learning, and that students should not be permanently pigeonholed into a specific temperament type. Although one's basic temperament creates a consistency in action that can be seen even at a very early age, the strength of one's preference may change over time as one is encouraged to practice and use an opposite preference. For example, nurses with a feeling preference may move further toward a thinking preference in graduate school, where they explore ways of knowing in nursing through theory and research.

We have found a focus on temperament types a useful framework for adapting theories and research from education to the design of class participation activities. If faculty members are aware of the potential presence of students with various temperament types, they can design class participation experiences that will encourage "trying out" different preferences by all students, thus encouraging personal growth. Although each of the four preferences has implications for nurse educators in relation to students' class participation, this article uses the introversion/extroversion preference to illustrate some of these implications. As indicated in Table 1, all four of those temperament types that comprise $1 \%$ of the population, are composed of the introverted preference. Thus, it seems important for nurse educators to include in their courses some activities that encourage understanding and participation of this temperament type.

In the process of designing these activities, the following three factors should be considered in relation to the introversion/extroversion preference: the value of class participation, the process for facilitating participation, and the evaluation of participation.

\section{Value of Class Participation}

Probably all nurse educators struggle with the problem of how to ensure that important content is "covered" and still provide adequate time for class discussion. Implicit in this struggle is the realization that participation in class discussion does provide important benefits not obtained in the lecture, or didactic, approach.

Beyer notes that the term cover means to hide or obscure, indicating a need for educators to resist the impulse to structure classrooms wholly around teaching to "cover the content" (BK Beyer, personal communication, 1987). The didactic method of instruction, in which the nurse educator lectures and the students take notes, memorize them, and feed the information back on examinations, robs students of important opportunities for in-depth exploration of content and for development of critical-thinking skills. Beyer ${ }^{5}$ describes critical thinking as "judging the authenticity, worth, or accuracy of something," indicating a process that involves both analysis 
and evaluation. Didactic methods do not help students learn how to gather, assess, analyze, synthesize, and evaluate information - skills that are critical to the practice of nursing. Passive listening in class does not help students learn how to analyze the diverse logic of questions and problems that will face them in the clinical area. ${ }^{6}$ People learn more when they are active participants in their learning. ${ }^{7}$ Yet in many classrooms, it may be difficult for the introverted student to participate actively in the exchange of ideas. Thus, classroom experiences must be designed to facilitate comfortable classroom participation by introverted, as well as extroverted students.

\section{Process for Facilitating Class Participation}

Clear guidelines should be included with the course syllabus about the expectations of class participation and how it will be evaluated. During the first day of class, faculty members should explain the methods of teaching, why the methods will be used, and the goals for class learning. Specific information about expectations for class participation should be provided, and students should be encouraged to think about the problems that introverted types have in traditional class participation activities and to identify creative ways to facilitate participation by all students. It should be emphasized that the extroversion and introversion preferences are neither "good" nor "bad," and that students of different temperament types should attempt to understand a preference that is different from their own and try out new approaches to interacting in the classroom. This discussion can help to allay concerns of introverted students and increase extroverted students' awareness of the difficulty of an activity that may seem second nature to them.

Kurfiss $^{8}$ proposed that faculty members must take an active role to assist all students in cultivating thinking skills. Faculty members must help students develop what Ennis ${ }^{9}$ referred to as subject specificity, i.e., adequate knowledge of a particular subject is needed for critical thinking to occur. Various approaches to class discussion and written assignments can help build these skills.

\section{Class Discussion}

Class discussion probably is the approach most commonly used by educators to facilitate class participation. Preclass participation in a variety of readings may be enjoyable for the introverted student, who gains energy from solitary reflection, rather than from active contact with others. Discussing insights gained from these readings in the classroom, however, can be very difficult. Both faculty members and students must recognize that even though introverted students may find it more difficult to contribute to the class discussion, they typically think through what they want to say and, if provided adequate opportunity, often make significant and insightful comments. Comments that may at first thought seem irrelevant, but which may lead the discussion in new and creative directions, must not be dismissed.

Anderson ${ }^{10}$ suggested that the Socratic method of teaching, in which students are guided in purposefully thinking about an idea or an assumption and weighing logical arguments against one another, helps students think critically and make decisions as they clarify ideas and positions. This type of teaching strategy also can help to pace the discussion to allow time for the more introverted students to respond. Some students may find it easier to participate in class discussion if roles are assigned to them, such as being the "reporter" for a small group discussion. Faculty members should make spaces in class discussions to bring out the introverted students' 
comments - and to contain those extroverts who may talk a lot, but offer little substantive material. More participation is not necessarily better.

\section{Written Assignments}

Short, ungraded writing assignments can serve as a useful bridge for class participation by introverted students. Preclass written responses to assigned readings can serve as focal points for class discussion. This type of assignment also can help assure faculty that those students who do not readily participate orally in the discussion have participated through writing about the material.

Providing a few minutes for in- class writing can help introverted students momentarily retreat back into their solitude to reflect on their ideas and regain energy to pursue, through class participation, new approaches for learning. ${ }^{11}$ Another option for class participation in both small and large classes is to have students write brief answers to questions at the end of the class session, ${ }^{12}$ such as:

What is the most important thing I learned today?

What idea/topic do I want to know more about?

How did I participate in class today?

Use of writing strategies such as these requires little additional faculty time and effort, yet it encourages all students to reflect on the course content and may stimulate the inquiry process in learning. 13,14

\section{Evaluation of Class Participation}

Students probably spend more time preparing for a discussion class than for a lecture class. However, for the introverted student, it may be difficult to demonstrate this preparation. In designing methods for evaluating class participation, faculty members must assess participation by introverted students, which might not be readily apparent.

A system for evaluating students' participation and rewarding their work is necessary; students need to know how their participation will be evaluated. For example, classroom participation criteria can range from being present to teaching the class. Examples of observable activities that could contribute to a grade for class participation include being present and on time, asking questions, reporting on research studies or readings, critiquing research studies, applying literature or research to clinical situations, debating with classmates about interpretations of studies presented, and participating in group work and role play. Feedback from faculty members to students about the quality of participation is critical. If students are allowed to periodically review the record of their participation, they can monitor their status and discuss with faculty members any concerns they have about evaluation of their class participation.

\section{Conclusion}

Nurse educators need to think about ways to facilitate class participation by students of different temperament types so that the inherent value of class participation reaches all students. 
Introverted students need to gain skills in expressing their ideas orally in the classroom.

Extroverted students need to gain skills in listening to other voices. An understanding of the four basic temperament types can provide a useful framework for nurse educators. This framework can help to structure a supportive classroom environment that encourages students to value differences and to try out ways of interacting that are different from their own basic temperament, providing them with an important dimension of personal growth.

\section{References}

1. Campbell J, ed. The Portable Jung. New York: Viking Press; 1971.

2. Keirsey D, Bates M. Please Understand Me. Del Mar, CA: Prometheus Nemesis Books; 1984.

3. Myers IB. Introduction to Type. Palo Alto, CA: Consulting Psychologists Press; 1989.

4. Brown HN. Factors that Affect Success in Nusing Education: An Exploratory Study. Greensboro: University of North Carolina; 1981. Dissertation.

5. Beyer BK. Practical Strategies for the Teaching of Thinking. Boston: Allyn and Bacon; 1987.

6. Beck SE, Bennett A, McLeod R, Molyneaaux D. Review of research on critical thinking in nursing education. In: Allen LR, ed. Review of Research in Nursing Education. Vol. V. New York: National League for Nursing; 1992.

7. Bevis BO, Watson J. Toward a Caring Curriculum: A New Pedagogy for Nursing. New York: National League for Nursing; 1989.

8. Kurfiss JG. Critical Thinking: Theory, Research, Practice, and Possibilities. Washington, DC: Association for Study of Higher Education: 1988. ASHE-ERIC Higher Education Report No. 2.

9. Ennis R. Critical thinking and subject specificity: clarification and needed research. Educ Res. 1989; 18(3)4-10.

10. Anderson J. Socrates as an educator. In: Anderson J, ed. Studies in Imperlal Philosophy. Sidney, Australia: Angus \& Robertson; 1961.

11. Bradley-Springer L. Discovery of meaning through imagined experience, writing, and evaluation. Nurse Educ. 1993; 18(5):5-10.

12. Blanchard KH, Johnson S. One Minute Manager. New York: Morrow; 1982.

13. Allen DG, Bowers B, Diekelmann N. Writing to learn: a reconceptualization of thinking and writing in the nursing curriculum. J Nurs Educ. 1989; 28(1):6-11.

14. Sorrell JM. Writing as inquiry in qualitative nursing research: elaborating the web of meaning. In: Chinn P, ed. Advances in Methods of Inquiry for Nursing. Gaithersburg, MD: Aspen Publishers; 1994. 